\title{
Aproveitamento de materiais alternativos na produção de mudas de tomateiro sob adubação foliar ${ }^{1}$
}

\author{
Use of alternative materials in the production of tomato seedlings under foliar \\ fertilisation
}

\author{
José Valdenor da Silva Júnior ${ }^{2 *}$, Márkilla Zunete Beckmann-Cavalcante ${ }^{3}$, Leonardo Pereira da Silva Brito ${ }^{4}$, \\ Rodrigo Cirqueira Avelino ${ }^{4}$ e Ítalo Herbert Lucena Cavalcante ${ }^{3}$
}

\begin{abstract}
RESUMO - A utilização dos resíduos orgânicos na composição dos substratos para mudas significa uma alternativa à reciclagem desses materiais. Objetivou-se avaliar as características agronômicas de mudas de tomateiro produzidas em materiais regionais alternativos utilizados como substrato e sob adubação foliar. O experimento foi conduzido em ambiente protegido no Campus da Universidade Federal do Piauí, em Bom Jesus-PI. Utilizou-se o delineamento experimental inteiramente casualizado, com os tratamentos distribuídos em esquema fatorial 5x2, referentes a cinco materiais utilizados como substratos na presença e ausência de adubação foliar (Vitam $\left.{ }^{\circledR}\right)$, com quatro repetições. Os materiais constaram de: 1) solo + areia + esterco bovino; 2) paú de buriti; 3) resíduo de carnaúba + casca de arroz; 4) resíduo de carnaúba em pó e 5) resíduo de carnaúba semi-decomposto. O cultivo foi feito em bandeja de poliestireno expandido com 128 células. Foram avaliados porcentagem de emergência, índice de velocidade de emergência, altura de planta, número de folhas, diâmetro do caule, comprimento da maior raiz, volume de raiz, massa fresca e massa seca da parte aérea e da raiz e massa seca total. O resíduo de carnaúba com casca de arroz e resíduo de carnaúba semi-decomposto apresentaram médias significativamente superiores aos demais materiais para todas as variáveis estudadas, exceto para a porcentagem de emergência e índice de velocidade de emergência. Independentemente do material usado como substrato na formação de mudas de tomateiro, exceto para o resíduo de carnaúba em pó, a aplicação de adubação foliar proporciona mudas de melhor qualidade.
\end{abstract}

Palavras-chave: Lycopersicon esculentum Mill.. Nutrição mineral, Propagação. Resíduos orgânicos.

\begin{abstract}
The use of organic waste in the composition of substrates for seedlings can be an alternative to recycling these materials. This study aimed to evaluate the agronomic characteristics of tomato seedlings grown with regional alternative materials being used as substrates and under foliar fertilisation. The experiment was conducted in a protected environment on the campus of the Federal University of Piauí, in Bom Jesus in the state of Piauí, Brazil. A completely randomised experimental design was used, with the treatments arranged in a $5 \times 2$ factorial scheme, corresponding to the five materials used as substrates, with and without foliar fertilization (Vitam ${ }^{\circledR}$ ), and with four replications. The materials consisted of: 1) soil, sand and cattle manure; 2) decomposed stem of the moriche palm [paú de buriti]; 3) carnauba residue with rice husks; 4) carnauba powder; 5) semi-decomposed carnauba residue. The seeds were grown in expanded polystyrene trays of 128 cells. The following were evaluated: Percentage emergence; speed of emergence index; plant height; number of leaves; stem diameter; length of the longest root; root volume; fresh and dry weight of the shoot and root; and total dry weight. The carnauba residue with rice husks and the semi-decomposed carnauba residue presented averages which were significantly superior to the other materials for all the studied variables, except for percentage emergence and speed of emergence index. In the production of tomato seedlings, regardless of the material used as substrate, and except for the carnauba powder, application of foliar fertilisation results in better quality seedlings.
\end{abstract}

Key words: Lycopersicon esculentum Mill. Mineral nutrition, Propagation. Organic waste.

\footnotetext{
*Autor para correspondência

${ }^{1}$ Recebido para publicação em 22/08/2011; aprovado em 26/12/2013

Parte da Dissertação de Mestrado do primeiro autor apresentada ao Programa de Pós-Graduação em Agronomia/Solos e Nutrição de Plantas, Universidade Federal do Piauí "Campus Prof ${ }^{a}$ Cinobelina Elvas/CPCE-UFPI

${ }^{2}$ Programa de Pós-Graduação em Agronomia - Solos e Nutrição de Plantas, Universidade Federal do Piauí, Campus Prof a Cinobelina Elvas, Rodovia Municipal Bom Jesus - Viana Km 01, Bom Jesus-PI, Brasil, valdenor.jr@ufpi.edu.br

${ }^{3}$ Campus de Ciências Agrárias, Universidade Federal do Vale do São Francisco, Petrolina-PE, Brasil, markilla.beckmann@ univasf.edu.br, italo. cavalcante@univasf.edu.br

${ }^{4}$ Departamento de Engenharias, Campus Profa. Cinobelina Elvas, Universidade Federal do Piauí, Curso de Pós-Graduação em Fitotecnia, Bom Jesus-PI, Brasil, leonardobrito@ufpi.edu.br, rodrigoc.avelino@ufpi.edu.br
} 


\section{INTRODUÇÃO}

A produção de mudas de hortaliças constituise em uma das etapas mais importantes do sistema produtivo, influenciando diretamente o desempenho nutricional e produtivo das plantas, o qual se baseia no grau de desenvolvimento empresarial e, principalmente, na pesquisa de melhores fontes e combinações de substratos com propriedades físicas e químicas ideais (CAMPANHARO et al., 2006; MENEZES JÚNIOR et al., 2000; SILVEIRA et al., 2002).

Essa produção de mudas depende da utilização de substratos, sendo limitada, muitas vezes, pelo seu alto custo. Neste sentido, o uso de resíduos orgânicos como fornecedores de nutrientes e suporte para compor substratos pode representar uma alternativa para diminuir o custo de produção das mudas hortícolas (BRITO et al., 2010; CARRIJO; LIZ; MAKISHIMA, 2002; MORAL et al., 2005;).

O substrato é um dos insumos que têm se destacado em importância devido à sua ampla utilização na produção de mudas hortícolas (SILVEIRA et al., 2002), uma vez que exerce grande influência no crescimento das plantas. A utilização dos resíduos da agroindústria, como componente de substratos, minimizam o descarte a céu aberto ou em aterros sanitários, e consequentemente o acúmulo dos mesmos no ambiente (CORREIA et al., 2003).

No entanto, antes de recomendar o uso de qualquer resíduo é preciso conhecer o potencial de utilização e determinar critérios técnicos para seu máximo aproveitamento, tornando-se necessário caracterizar os diferentes materiais encontrados nas diferentes regiões do país e torná-los disponíveis como substratos agrícolas (ANDRIOLO et al., 1999).

De acordo com Costa et al. (2007) substratos à base de compostagem de resíduo de algodão, procedentes da indústria têxtil, mostraram eficiência na produção de mudas de tomateiro produzidas em bandejas de 128 células. Rodrigues et al. (2010) avaliando a produção de mudas de tomateiro, utilizando bandejas de diferentes volumes de células e substratos à base de solo e composto orgânico, verificaram que a interação entre bandeja de 72 células e substrato com $7 \%$ de composto orgânico foi a mais viável para o crescimento das mudas. Steffen et al. (2010) estudando diferentes formulações de substratos compostos por solo e vermicompostos, obtidos pela combinação de diferentes proporções de casca de arroz (natural e carbonizada) e esterco bovino, concluíram que a casca de arroz assim como o húmus de minhoca são materiais com potencial para serem utilizados como substratos para produção comercial de mudas de tomateiro e alface.

No cultivo de espécies olerícolas, de alto valor econômico, como é caso do tomateiro, a aplicação de fertilizantes foliares, incluindo o $\mathrm{Ca}$ e o B, tem sido praticada pelos produtores, visando o aumento de produção e a qualidade dos frutos (PEREIRA; MELLO, 2002). Entretanto, há escassez de pesquisas no Brasil, sobre os efeitos da fertilização foliar na produção de mudas de hortaliças.

Mediante a importância do uso e formulação de substratos para a produção de mudas hortícolas, o presente estudo objetivou avaliar as características agronômicas de mudas de tomateiro produzidas em materiais regionais alternativos utilizados como substrato e sob adubação foliar, nas condições de Bom Jesus-PI.

\section{MATERIAL E MÉTODOS}

O experimento foi conduzido no período de 29/03/2010 a 05/05/2010, totalizando 38 dias, em casa de vegetação no Setor de Horticultura do Campus Prof ${ }^{a}$. Cinobelina Elvas da Universidade Federal do Piauí - CPCE/UFPI, situado no município de Bom Jesus, Piauí, localizado às seguintes coordenadas geográficas $09^{\circ} 04^{\prime} 28^{\prime \prime} \mathrm{S}, 44^{\circ} 21^{\prime} 31^{\prime \prime} \mathrm{O}$ e, altitude média de $277,0 \mathrm{~m}$.

O experimento foi conduzido em ambiente protegido do tipo "capela", com as seguintes dimensões internas: 5,0 m de comprimento e 3,0 m de largura (área total de $15,0 \mathrm{~m}^{2}$ ) e pé direito de $3,0 \mathrm{~m}$, orientado no sentido leste-oeste, protegido com tela de polipropileno com 50\% de sombreamento, sobre todos os lados da estrutura metálica (parte superior e laterais) e, coberto com polietileno de baixa densidade, com $150 \mu$ de espessura.

Monitoraram-se diariamente, durante a execução do experimento, a temperatura do ar, a umidade relativa do ar e a intensidade luminosa no interior do ambiente, três vezes ao dia (às 8:00; 12:00 e 16:00 h). Os dados de temperatura do ar (Figura. 1 A) e umidade relativa do ar (Figura $1 \mathrm{~B}$ ) foram obtidos através de termo-higrômetro digital (Quimis $®$ ) instalado na parte central do ambiente, com o sensor disposto a $1,5 \mathrm{~m}$ de altura do solo. A intensidade luminosa foi aferida através de luxímetro digital (Instrutherm ${ }^{\circledR}$ ) e os dados se encontra na Figura 1 C.

As mudas foram conduzidas em bandejas de poliestireno expandido (isopor), com 128 células dispostas em duas bancadas perpendiculares com dimensões de 4,9 m de comprimento por 1,0 m de largura e $1,0 \mathrm{~m}$ de altura. Foram utilizadas sementes de tomateiro cv. Caline IPA 6 (Topseed ${ }^{\circledR}$ ) de hábito de crescimento indeterminado, pertencente ao grupo industrial.

A semeadura ocorreu no dia 29 de março de 2010, colocando-se duas sementes por célula. Aos nove dias após a semeadura (DAS) foi feito o desbaste das mudas deixando uma planta por célula e com auxílio de um pulverizador costal foi aplicado oito litros de calda de fertilizante foliar organo mineral classe B (Vitan ${ }^{\circledR}$ - Sudoeste Agropecus Ind. 
Com. Ltda), na dosagem $100 \mathrm{ml} 100 \mathrm{~L}^{-1}$, nos tratamentos com adubação foliar (CAF). As adubações foliares foram repetidas a cada sete dias até o final do experimento conforme recomendações do fabricante, totalizando quatro aplicações. $\mathrm{O}$ adubo foliar organo mineral apresenta em sua composição

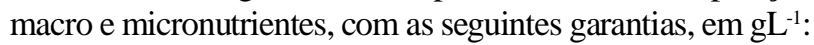
$\mathrm{N}$ - 87; P2O5- 116; K2O - 116; Ca - 14,5; S - 34,8; Mg - 7,2; $\mathrm{B}-8,7 ; \mathrm{Cu}-2,9 ; \mathrm{Mn}-7,2 ; \mathrm{Mo}-2,9$ e Zn - 14,5.

As plantas foram irrigadas duas vezes por dia em intervalos de oito horas utilizando um pulverizador costal manual. Os tratamentos fitossanitários corresponderam a uma aplicação de 1,3 litros de calda do inseticida

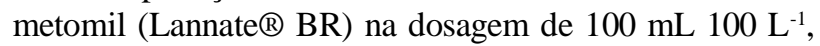
para controle do pulgão-verde (Myzus persicae) e uma desinfecção com hipoclorito de sódio $2,5 \%$ por 20 minutos, para esterilização prévia das bandejas de cultivo.

O delineamento experimental adotado foi inteiramente casualizado, com os tratamentos distribuídos em esquema fatorial $5 \times 2$, referentes a cinco materiais utilizados como substratos na presença ou ausência de adubação foliar. Os materiais usados como substratos foram: 1) solo + areia
+ esterco bovino (SAEB), na proporção 1:1:1 (v/v); 2) paú de buriti $(\mathrm{PaB})$, originado da decomposição natural do caule da palmeira buriti (Mauritia flexuosa); 3) resíduo de carnaúba (Copernicia prunifera) + casca de arroz (Oriza sativa) in natura (RCCA); 4) resíduo de carnaúba em pó (RCP); e 5) resíduo de carnaúba semi-decomposto (RCSD). Foram utilizadas quatro repetições, cada uma composta por 16 plantas centrais de cada bandeja.

Os resíduos RCCA e RCP foram provenientes de usinas de transformação, pelo processo industrial, do pó de carnaúba em cera. O RCCA é o resíduo, gerado no processo de destilação do pó, processo no qual, é adicionado casca de arroz in natura para facilitar a extração da cera (ALVES; COELHO, 2006). O RCP também é gerado no processo de destilação, no entanto, a casca de arroz é retirada desse resíduo pelo processo de peneiramento, para ser reutilizada por algumas usinas. O RCSD é a bagana semi-decomposta, obtida pela trituração mecânica da folha de carnaúba, seca ao sol por um período de 6 a 12 dias, para retirada do pó (ALVES; COELHO, 2006) e, "deixada em repouso" na própria área de extração.

Figura 1 - Temperatura do ar (A), umidade relativa do ar (B) e intensidade luminosa (C) no interior do ambiente protegido, monitorada diariamente a partir de 1 a 37 dias após a semeadura (DAS)

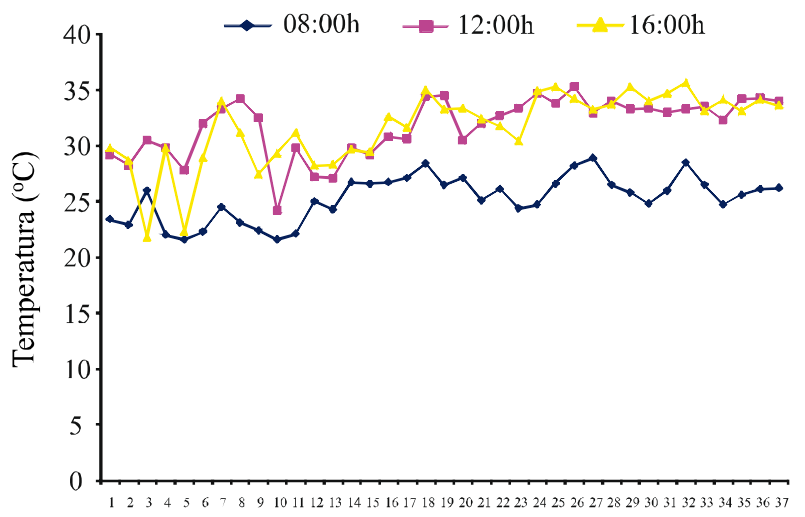

DAS

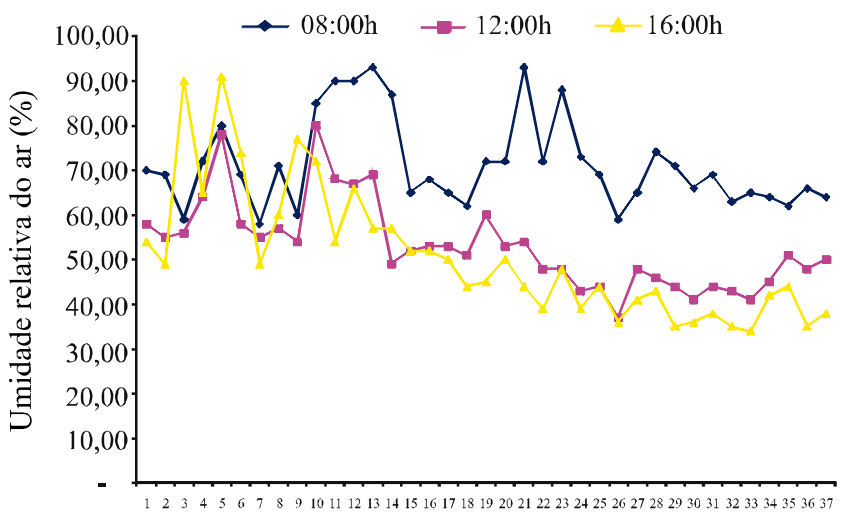

DAS

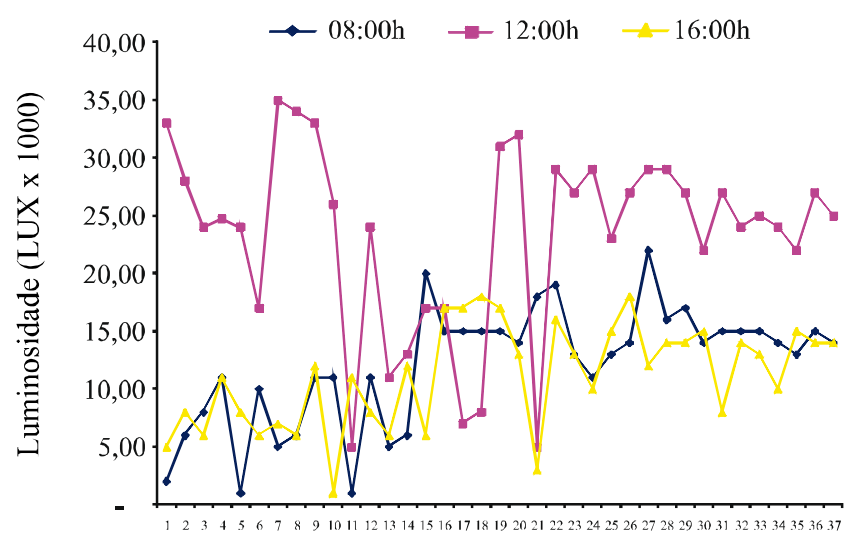

DAS 
Os materiais utilizados com substratos foram esterilizados em autoclave vertical com temperatura de $120^{\circ} \mathrm{C}$, por um período de uma hora, para prevenir a ação de possíveis patógenos do solo presentes nesses materiais.

A caracterização física e química dos materiais utilizados como substratos para a produção de mudas foi realizada no Laboratório de Biociências, CPCE/UFPI, Bom Jesus-PI. A granulometria foi determinada pelo tamisamento via seca. Os materiais foram inicialmente passados em uma peneira com malha de $5,0 \mathrm{~mm}$, para homogeneização, em seguida, foram pesados $100 \mathrm{~g}$ de cada material seco ao ar, os quais foram peneirados em um jogo acoplado de peneiras com malha de 2,$0 ; 1,7 ; 0,85 ; 0,6 ; 0,3$ e $0,25 \mathrm{~mm}$, e agitado por 5 minutos. As frações retidas em cada peneira foram pesadas e calculadas a porcentagem sobre o peso total das amostras (Figura 2).

Quanto à caracterização química dos substratos (Tabela 1) foram analisados: $\mathrm{pH}$ e condutividade elétrica (CE), de acordo com (BRASIL, 2007) e os teores totais dos macronutrientes: nitrogênio $(\mathrm{N})$, fósforo $(\mathrm{P})$, potássio $(\mathrm{K})$, cálcio $(\mathrm{Ca})$ e magnésio $(\mathrm{Mg})$, determinados em extrato nítrico-perclórico (MALAVOLTA et al., 1997).

$\mathrm{Na}$ caracterização física (Tabela 2) foram realizadas análises de densidade úmida (DU) e densidade seca (DS) segundo procedimento de (BRASIL, 2007) e, capacidade de retenção de água (CRA), espaço de aeração (EA) e volume dos poros (VP), determinados conforme os procedimentos descritos por Beckmann-Cavalcante (2007).

Durante os primeiros nove dias após a semeadura foram realizadas contagens diárias do número de plântulas emergidas, e com a obtenção desses dados, realizaram-se análises de porcentagem de emergência (\%E) e índice de velocidade de emergência (IVE). Consideraram-se sementes emergidas aquelas cujos cotilédones surgiram sobre o substrato. $\mathrm{O}$ índice de velocidade de emergência foi determinado pelo somatório do número de plântulas normais, emergidas a cada dia, dividido pelo número de dias decorridos entre a semeadura e a emergência, de acordo com a fórmula descrita por Maguire (1961).

Aos 37 DAS, dezesseis plantas centrais de cada bandeja foram separadas em parte aérea e sistema radicular e determinadas as seguintes características: a) altura de planta, expressa em $\mathrm{cm}$, medida com régua milimetrada, a partir do coleto até a gema apical; b) número de folhas; c) diâmetro do caule, expresso em mm, medido na base do coleto, utilizando-se um paquímetro digital (Digimess ${ }^{\circledR}$ ) com precisão de $0,01 \mathrm{~mm}$; d) comprimento da maior raiz, expresso em $\mathrm{cm}$, medida com régua milimetrada, a partir do coleto até a extremidade da maior raiz; e) volume de raiz, expresso em $\mathrm{cm}^{3}$, realizado por meio da medição do deslocamento da coluna de água em proveta graduada, ou seja, colocando-se as raízes, após lavagem, em proveta contendo um volume conhecido de água (100 mL). Pela diferença, obteve-se a resposta direta do volume de raízes, pela equivalência de unidades $\left(1 \mathrm{~mL}=1 \mathrm{~cm}^{3}\right)$, segundo metodologia descrita por Basso (1999); f) massa fresca e massa seca da parte aérea e da raiz, expressa em grama, pesada em balança com precisão de 0,001 g (Bioprecisa $\left.{ }^{\circledR}\right)$. Para determinação da massa seca, o material vegetal foi colocado em estufa com circulação forçada de ar à temperatura de $65^{\circ} \mathrm{C}$ até atingir peso constante; g) massa seca total, expressa em gramas, obtida pela soma das massas secas da parte aérea e da raiz.

Figura 2 - Distribuição do tamanho das partículas (\%) de materiais estudados para uso como substrato

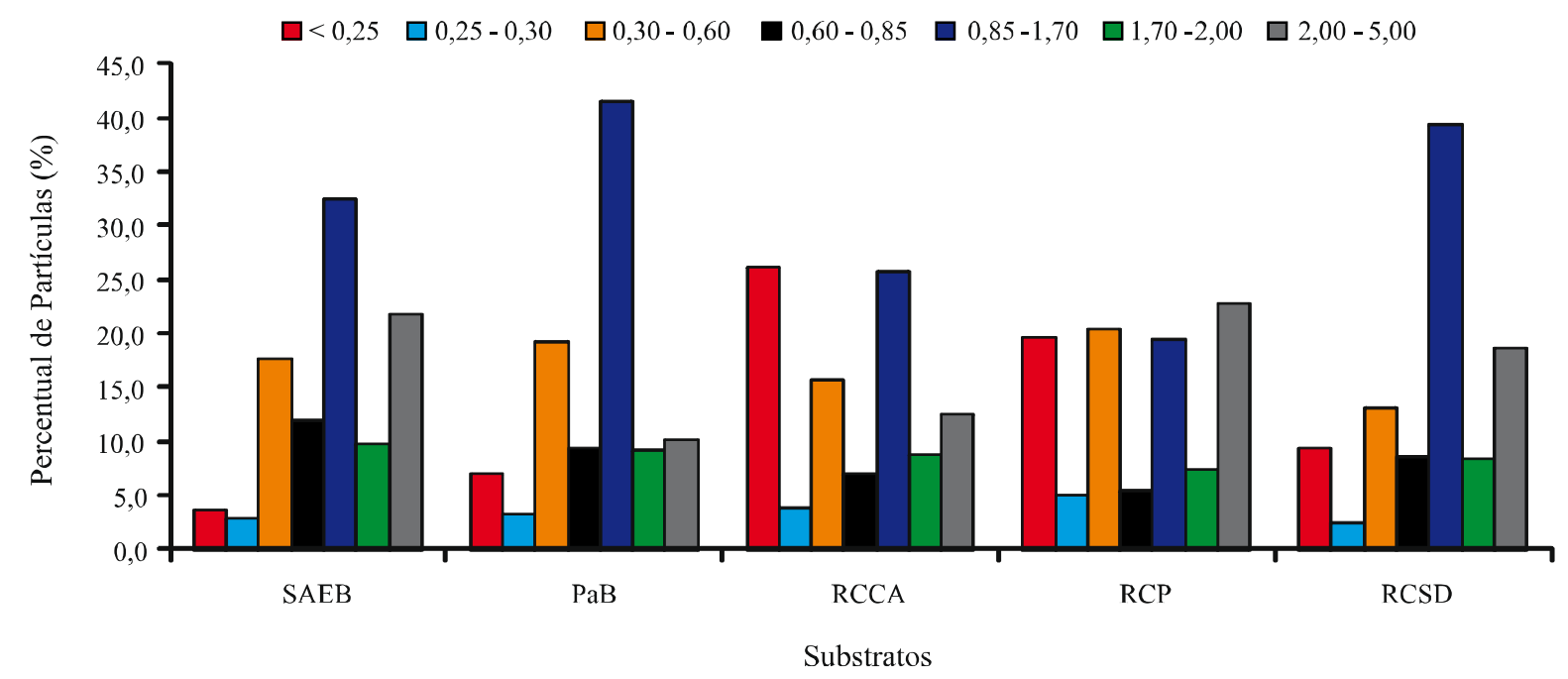

$\mathrm{SAEB}=$ Solo + areia + esterco bovino $; \mathrm{PaB}=$ paú de buriti $; \mathrm{RCCA}=$ resíduo de carnaúba + casca de arroz; $\mathrm{RCP}=$ resíduo de carnaúba em pó; $\mathrm{RCSD}=$ resíduo de carnaúba semi-decomposto 
Tabela 1 - Valores de pH, condutividade elétrica $(\mathrm{CE})$ e teores totais de nitrogênio $(\mathrm{N})$, fósforo $(\mathrm{P})$, potássio $(\mathrm{K})$, cálcio $(\mathrm{Ca})$ e magnésio $(\mathrm{Mg})$, em materiais utilizados como substratos

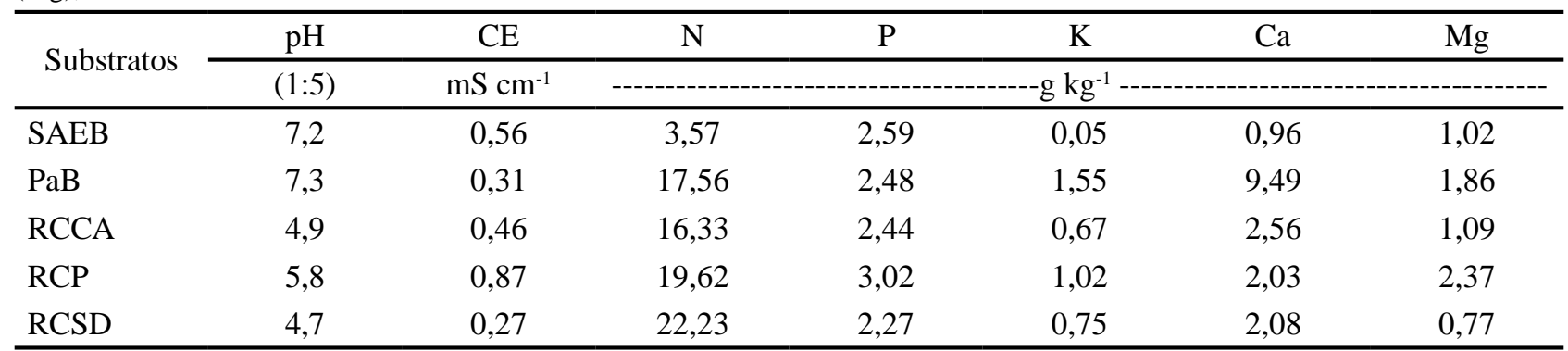

SAEB: solo + areia + esterco bovino (1:1:1); PaB: paú de buriti; RCCA: resíduo da carnaúba + casca de arroz; RCP: resíduo da carnaúba em pó; RCSD: resíduo da carnaúba semi-decomposto

Tabela 2 - Densidade úmida (DU), densidade seca (DS), capacidade de retenção de água (CRA), espaço de aeração (EA) e volume dos poros (VP) de materiais alternativos utilizados como substratos

\begin{tabular}{lccccc}
\hline \multicolumn{1}{c}{ Substratos } & DU $\left(\mathrm{kg} \mathrm{m}^{-3}\right)$ & DS $\left(\mathrm{kg} \mathrm{m}^{-3}\right)$ & CRA $(\%)$ & EA $(\%)$ & VP $(\%)$ \\
\hline SAEB & 1467 & 1208 & 39 & 10 & 49 \\
PaB & 625 & 124 & 57 & 35 & 93 \\
RCCA & 582 & 219 & 41 & 48 & 89 \\
RCP & 615 & 185 & 70 & 20 & 90 \\
RCSD & 633 & 172 & 45 & 45 & 90 \\
\hline
\end{tabular}

SAEB: solo + areia + esterco bovino; PaB: paú de buriti; RCCA: resíduo da carnaúba + casca de arroz; RCP: resíduo da carnaúba em pó; RCSD: resíduo da carnaúba semi-decomposto

Os dados foram submetidos à análise de variância, e os tratamentos comparados entre si pelo teste de Tukey, através do programa computacional Assistat (SILVA; AZEVEDO, 2006).

\section{RESULTADOS E DISCUSSÃO}

Opercentual de emergência (\%E) foi influenciado pelos diferentes materiais utilizados como substratos. Os materiais paú de buriti $(\mathrm{PaB})$, resíduo de carnaúba semi-decomposto (RCSD), resíduo de carnaúba + casca de arroz (RCCA) e resíduo de carnaúba em pó (RCP) não diferiram estatisticamente entre si, entretanto foram superiores estatisticamente ao solo + areia + esterco bovino (SAEB) (Tabela 3).

Os melhores percentuais de emergência observados nos materiais PaB, RCCA, RCP e RCSD, podem ser atribuídos à maior capacidade de retenção de água destes materiais (Tabela 2), mantendo a água nas proximidades das sementes, o que é desejável para obtenção da uniformidade de emergência e um bom estande (CARVALHO; NAKAGAWA, 2000).
Tabela 3 - Valores do percentual de emergência (\%E) e índice de velocidade de emergência (IVE) de plântulas de tomateiro, cultivadas em diferentes materiais alternativos utilizados como substratos

\begin{tabular}{lcc}
\hline \multicolumn{1}{c}{ Causa de variação } & $\% \mathrm{E}$ & \multicolumn{1}{c}{ IVE } \\
\hline S (Valor "F") & $6,42^{* *}$ & $28,09^{* *}$ \\
SAEB & $87,74 \mathrm{~b}$ & $2,89 \mathrm{c}$ \\
PaB & $98,93 \mathrm{a}$ & $3,78 \mathrm{a}$ \\
RCCA & $98,44 \mathrm{a}$ & $3,44 \mathrm{~b}$ \\
RCP & $98,15 \mathrm{a}$ & $2,84 \mathrm{c}$ \\
RCSD & $97,46 \mathrm{a}$ & $3,48 \mathrm{ab}$ \\
AF (valor "F") & $0,11^{\mathrm{ns}}$ & $0,46^{\mathrm{ns}}$ \\
CAF & 96,43 & 3,26 \\
SAF & 95,86 & 3,31 \\
Interação S x AF ("F") & $0,13^{\mathrm{ns}}$ & $0,46^{\mathrm{ns}}$ \\
C.V. (\%) & 5,49 & 6,61 \\
\hline
\end{tabular}

DMS = diferença mínima significativa; $\mathrm{CV}=$ coeficiente de variação; $\mathrm{S}=$ substrato; $\mathrm{SAEB}=\mathrm{Solo}+$ areia + esterco bovino; $\mathrm{PaB}=$ paú de buriti $\mathrm{RCCA}=$ resíduo de carnaúba + casca de arroz; $\mathrm{RCP}=$ resíduo de carnaúba em pó; $\mathrm{RCSD}$ = resíduo de carnaúba semi-decomposto; $\mathrm{AF}=$ condição de adubação foliar; $\mathrm{CAF}=$ com adubação foliar; $\mathrm{SAF}=$ sem adubação foliar; $n s=$ não significativo; **= significativo ao nível de $1 \%$ de probabilidade; as médias seguidas pela mesma letra em cada coluna, não diferem entre si, pelo teste de Tukey 
Comparativamente aos resultados apresentados por Costa et al. (2007) ao estudar a fibra da casca de coco como substrato para obtenção de mudas de tomateiro, observa-se que os resultados deste trabalho são similares ou superiores, visto que os referidos autores obtiveram médias de emergência variando de 36,06 a 92,18\%. Adicionalmente, é pertinente destacar que no referido trabalho o substrato comercial Hortimix promoveu média de 90,62\% de emergência, resultado inferior aos demais tratamentos, exceto o material SAEB que obteve média de $87,74 \%$ de percentual de emergência (Tabela 3). Há concordância também em relação à emergência de plântulas com os resultados registrados por Luz et al. (2004), que estudou a combinação de vermiculita com composto de lixo urbano para produção de mudas de tomateiro, obtendo médias do percentual de emergência variando de 93,00 a 96,10\%.

O material $\mathrm{PaB}$ conferiu o maior índice de velocidade de emergência (IVE), não diferindo estatisticamente do RCSD, enquanto o menor índice foi verificado para os materiais SAEB e RCP (Tabela 3), o que deve-se provavelmente ao menor espaço de aeração conferido por estes materiais (Tabela 2), permitindo inferir que o espaço de aeração do substrato pode constituir uma característica mais determinante na velocidade do processo de emergência da plântula.
Quanto ao IVE, as médias contidas na Tabela 3 são similares ou superiores as de Costa et al. (2007) bem como as de Sampaio et al. (2008), também em estudo de produção de mudas de tomateiro usando composições alternativas de substratos.

Para as variáveis altura de plantas, número de folhas, diâmetro do caule, comprimento da maior raiz e volume de raiz, houve interação entre os fatores. No entanto, para a variável diâmetro do caule, não houve interação, mas efeitos isolados de cada um dos fatores.

De acordo com a Figura 3 verifica-se que as plantas que receberam adubação foliar apresentaram resultados significativamente superiores àquelas não adubadas, indicando que nenhuma das composições de substrato apresentou características químicas suficientes para promover, sem a necessidade de adubação, o ótimo desenvolvimento das mudas de tomateiro, apesar das diferentes composições químicas (Tabela 1).

Comparando-se a Figura $3 \mathrm{C}$ com a 3 D observa-se a importância do espaço de aeração (Tabela 2) no desenvolvimento do sistema radicular, visto que as raízes de substratos com SAEB e RCP, aqueles com menor espaço de aeração, apresentaram volume radicular bem abaixo dos demais, enquanto o comprimento da maior raiz aproximou-

Figura 3 - Altura de plantas (A), número de folhas (B), comprimento da maior raiz (C) e volume de raízes (D) de mudas de tomateiro cv. Caline IPA 6 aos 37 DAS, em função da interação substratos e adubação foliar
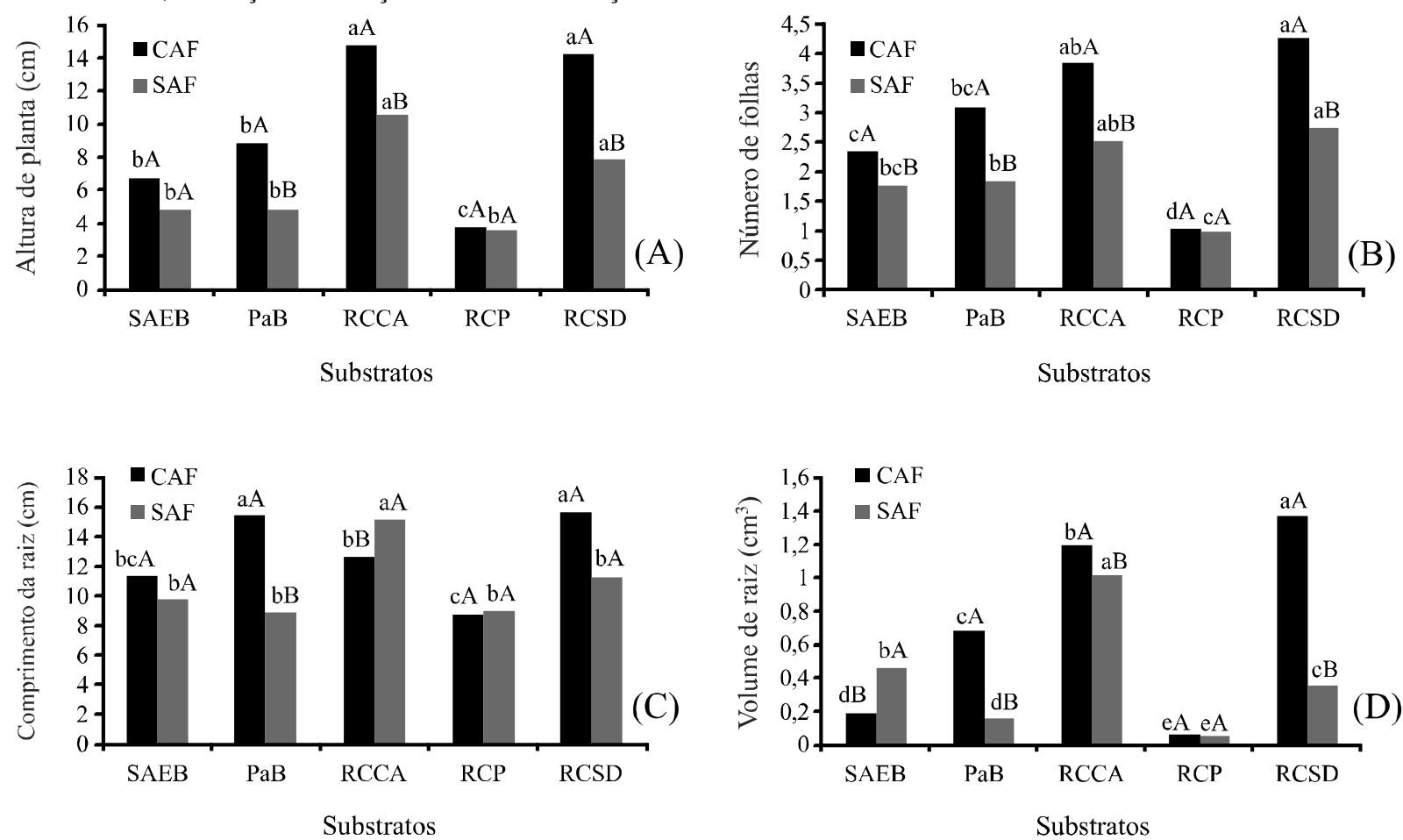

$\mathrm{SAEB}=$ Solo + areia + esterco bovino $\mathrm{PaB}=$ paú de buriti $\mathrm{RCCA}$ = resíduo de carnaúba + casca de arroz; $\mathrm{RCP}=$ resíduo de carnaúba em pó; $\mathrm{RCSD}=$ resíduo de carnaúba semi-decomposto; $\mathrm{CAF}$ = com adubação foliar; $\mathrm{SAF}=$ sem adubação foliar; médias seguidas pela mesma letra não diferem entre si pelo teste de Tukey ao nível de $1 \%$ de probabilidade; letra minúscula compara os substratos e maiúscula compara a presença ou ausência de adubação foliar 
se em média dos demais tratamentos. Entretanto, quanto ao desenvolvimento do sistema radicular, Bloom et al. (2003) afirmaram que as reações envolvidas nesse processo ainda não são totalmente conhecidas, em parte devido às diferentes respostas em função das espécies e, adicionalmente, os fatores externos que influenciam no desenvolvimento radicular incluindo nitrogênio inorgânico, $\mathrm{pH}$ e potencial redox que atuam simultaneamente.

Para as variáveis massa fresca e seca também houve interação significativa entre esses fatores. Seguindo a tendência das demais variáveis, os substratos RCCA e RCSD foram superiores aos outros substratos, enquanto RCP, invariavelmente promoveu os menores valores, o que teve influência direta das características químicas e físicas desses substratos (Tabelas 1 e 2).

$\mathrm{Na}$ Figura 4, destaca-se o efeito da aplicação da adubação foliar sobre as mudas de tomateiro para a maioria das variáveis estudadas e entre os materiais utilizados como substratos, com exceção para as variáveis MFPA (Figura. 4 A), MFR (Figura 4 B), MSPA (Figura 4 C) e

Figura 4 - Massa fresca da parte aérea (A), massa fresca da raiz (B), massa seca da parte aérea (C), massa seca da raiz (D) e massa seca total (E) de mudas de tomateiro cv. Caline IPA 6 aos 37 DAS, em função da interação substratos e adubação foliar

(A)

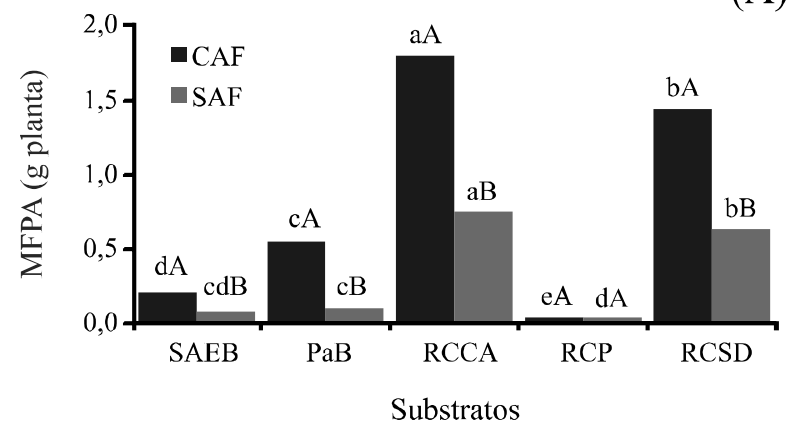

(C)

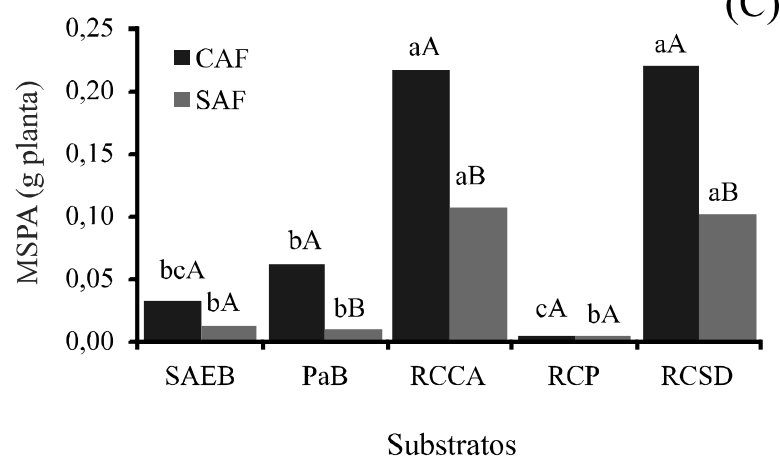

(B)

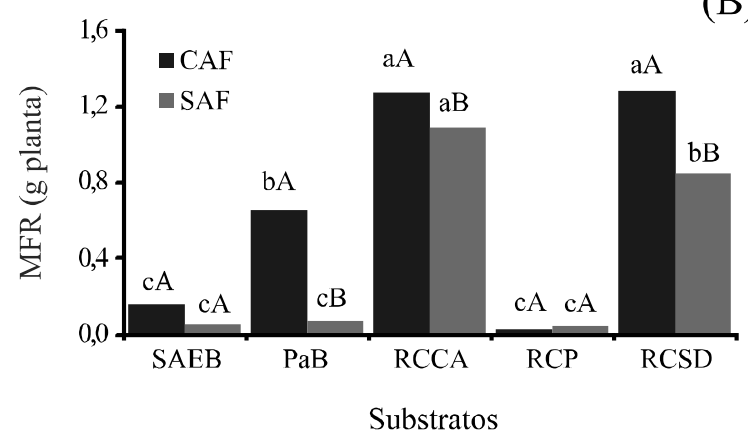

(D)

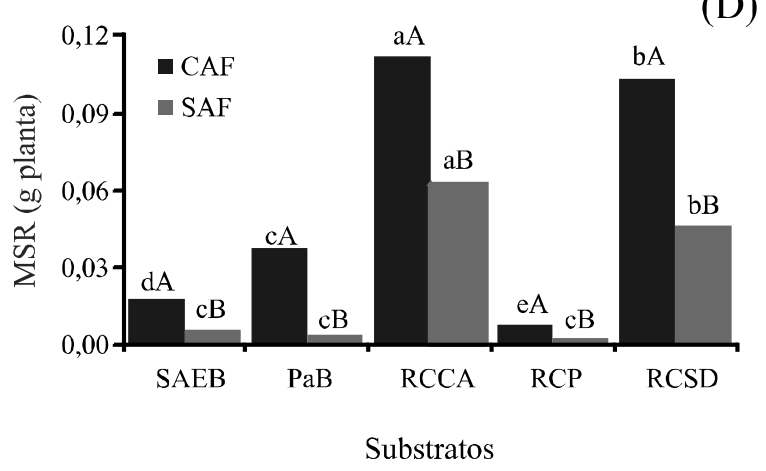

(E)

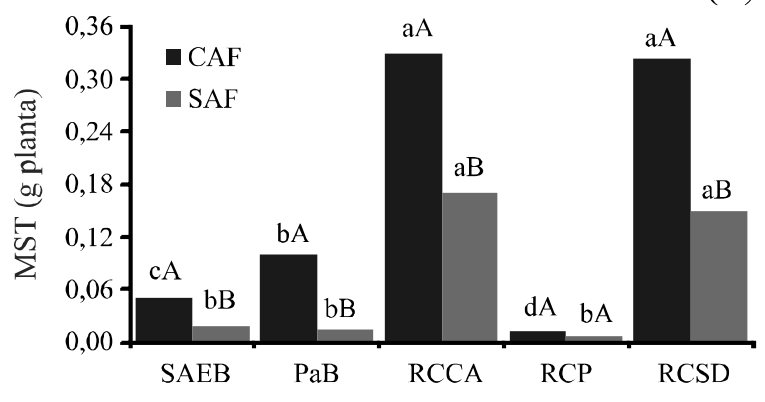

Substratos

$\mathrm{SAEB}=$ Solo + areia + esterco bovino $\mathrm{PaB}=$ paú de buriti; $\mathrm{RCCA}=$ resíduo de carnaúba + casca de arroz; $\mathrm{RCP}=$ resíduo de carnaúba em pó; $\mathrm{RCSD}=$ resíduo de carnaúba semi-decomposto; $\mathrm{CAF}=$ com adubação foliar; $\mathrm{SAF}=$ sem adubação foliar; médias seguidas pela mesma letra não diferem entre si pelo teste de Tukey ao nível de $1 \%$ de probabilidade; letra minúscula compara os substratos e maiúscula compara a presença ou ausência de adubação foliar 
MST (Figura 4 E) para o material RCP e, MFR (FIG. 4 B) e MSPA (Figura 4 C) para o material SAEB.

Em uma avaliação global da Figura 4 ressaltase que os tratamentos que receberam adubação mineral com macro e micronutrientes promoveram resultados significativamente superiores àqueles sem o fornecimento do insumo, seguindo assim a tendência das demais variáveis estudadas e relevando a importância do balanço nutricional adequando na formação de mudas de tomateiro, como também enfatizam de acordo com Carrijo; Liz e Makishima (2002), quando os substratos não possuem os nutrientes essenciais para as plantas, devem ser utilizados em combinação com adubos.

\section{CONCLUSÕES}

1.Os materiais resíduo de carnaúba + casca de arroz e resíduo de carnaúba semi-decomposto (RCSD) podem ser usados como substratos na produção de mudas de tomateiro;

2.Independentemente do material usado como substrato na formação de mudas de tomateiro, com exceção do resíduo de carnaúba em pó (RCP) e solo + areia + esterco bovino (SAEB), a aplicação de adubação foliar proporciona mudas de melhor qualidade.

\section{AGRADECIMENTOS}

À Fundação de Amparo à Pesquisa do Estado do Piauí (FAPEPI) pelo apoio financeiro (Processo 20.203.590/09) e ao CNPq pela bolsa de iniciação científica PIBIC do terceiro autor.

\section{REFERÊNCIAS}

ALVES, M. O.; COELHO, J. D. Tecnologia e relações sociais de produção no extrativismo da carnaúba no nordeste brasileiro. In: CONGRESSO DA SOCIEDADE BRASILEIRA DE ECONOMIA E SOCIOLOGIA RURAL, 44., Fortaleza. Anais... Fortaleza: Sociedade Brasileira de Economia e Sociologia Rural, 2006. p. 9. 1 CD-ROM.

ANDRIOLO, J. L. et al. Caracterização e avaliação de substratos para o cultivo do tomateiro fora do solo. Horticultura Brasileira, v. 17, n. 3, p. 215-219, 1999.

BASSO, S. M. S. Caracterização morfológica e fixação biológica de nitrogênio de espécies de Adesmia DC. e Lotus L. 1999. 268 f. Tese (Doutorado em Zootecnia) - Universidade Federal do Rio Grande do Sul, Porto Alegre, 1999.

BECKMANN-CAVALCANTE, M. Z. Características de substratos e concentrações de soluções nutritivas para o cultivo do crisântemo em vaso. 2007. 145 f. Tese (Doutorado em Agronomia) - Universidade Estadual Paulista, Jaboticabal, 2007.

BLOOM, A. J. et al. Root Development and Absorption of Ammonium and Nitrate from the Rhizosphere. Journal of Plant Growth Regulation, v. 21, p. 416-431, 2003.

BRITO, A. D. et al. Influência do pó de café coado na respiração microbiana do solo e sua utilização como substrato. Acta Tecnológica, v. 5, n. 2, p. 69-83, 2010.

CAMPANHARO, M. et al. Características físicas de diferentes substratos para produção de mudas de tomateiro. Caatinga. v. 19, n. 2, p.140-145, 2006.

CARRIJO, O. A.; LIZ, R. S.; MAKISHIMA, N. Fibra da casca do coco verde como substrato agrícola. Horticultura Brasileira, v. 20, n. 4, p. 533-535, 2002.

CARVALHO, N. M.; NAKAGAWA, J. Sementes: ciência, tecnologia e produção. 4. ed. Jaboticabal: Funep, 2000. 588 p.

CORREIA, D. et al. Uso do pó da casca de coco na formulação de substratos para formação de mudas enxertadas de cajueiro anão precoce. Revista Brasileira de Fruticultura, v. 25, n. 3, p. $557-558,2003$.

COSTA, C. A. et al. Fibra de coco e resíduo de algodão para substrato de mudas de tomateiro. Horticultura Brasileira, v. 25, n. 3, p. 387-391, 2007.

LUZ, J. M. Q. et al. Composto orgânico de lixo urbano e vermiculita como substrato para produção de mudas de alface, tomate e couve-flor. Bioscience Journal, v. 20, n. 1, p. 67-74, 2004.

MAGUIRE, J. D. Speed of germination aid in selection and evolution for sidling emergence and vigor. Crop Science, v. 2, n. 2, p. 176-177, 1961.

MALAVOLTA, E.; VITTI, G. C.; OLIVEIRA, S. A. Avaliação do estado nutricional das plantas: princípios e aplicações. Piracicaba: Potafos, 1997. 201 p.

BRASIL. MINISTÉRIO DA AGRICULTURA, PECUÁRIA E ABASTECIMENTO. Instrução normativa. DAS n ${ }^{\circ}$ 17, de 21 de maio de 2007. Diário Oficial [da] República Federativa do Brasil. Brasília, 24 de maio de 2007, seção 1, p. 8.

MENEZES JUNIOR, F. O. G. et al. Caracterização de diferentes substratos e seu desempenho na produção de mudas de alface em ambiente protegido. Horticultura Brasileira, v. 18, n. 3, p. 164-170, 2000.

MORAL, R. et al. Characterization of the organic matter pool in manures. Bioresource Technology, v. 96, n. 2, p. 153-158, 2005 .

PEREIRA, H. S; MELlO, S. C. Aplicações de fertilizantes foliares na nutrição e na produção do pimentão e do tomateiro. Horticultura Brasileira, v. 20, n. 4, p. 597-600, 2002.

RODRIGUES, E. T. et al. Produção de mudas de tomateiro em diferentes substratos e recipientes em ambiente protegido. Horticultura Brasileira, v. 28, n. 4, p. 483-488, 2010. 
SAMPAIO, R. A. et. al. Produção de mudas de tomateiro em substratos contendo fibra de coco e pó de rocha. Horticultura Brasileira, v. 26, n. 4, p. 499-503, 2008.

SILVA, F. A. S. E; AZEVEDO, C. A. V. A. New Version of The Assistat-Statistical Assistance Software. In: WORLD CONGRESS ON COMPUTERS IN AGRICULTURE, 4, Orlando-FL-USA: Anais... Orlando: American Society of Agricultural Engineers, 2006. p. 393-396.
SILVEIRA, E. B. et al. Pó de coco como substrato para produção de mudas de tomateiro. Horticultura Brasileira, v. 20, n. 2, p. 211-216, 2002.

STEFFEN, G. P. K. et al. Casca de arroz e esterco bovino como substratos para a multiplicação de minhocas e produção de mudas de tomate e alface. Acta Zoológica Mexicana (nueva serie), v. 26, Número Especial 2, p. 333343, 2010. 